\title{
Dilemas da democracia brasileira: república em Estado de Exceção permanente
}

\section{Dilemms of brazilian democracy: republic in permanent State of Exception}

\author{
Felipe Alves da Silva iD \\ Universidade de São Paulo (FFLCH-USP) \\ felipealves silva@yahoo.com
}

\begin{abstract}
Resumo
O ano de 2018 marcou os 30 anos da Constituição Federal de 1988 e da redemocratização no Brasil pós-Ditadura Militar. O presente estudo propõe-se a analisar criticamente a redemocratização, a partir de alguns conceitos de Carl Schmitt e Giorgio Agamben, a fim de mostrar os resquícios da ditadura - via dispositivos autoritários e excepcionais - dentro do próprio texto constitucional. Não se trata de minimizar os avanços introduzidos pelo novo texto constitucional em 1988, sobretudo com relação aos direitos e garantias fundamentais estabelecidos, mas analisar seriamente a ordem constitucional pelo viés da exceção e dos problemas ocasionados pela inscrição - e uso permanente - desses institutos no ordenamento jurídico. Sob uma análise crítica do constitucionalismo, adota-se o método de pesquisa bibliográfica e análise conceitual, mostrando como a democracia brasileira guarda relação com a ditadura, seguindo a mesma lógica de funcionamento
\end{abstract}

Palavras-chave: Brasil, democracia, exceção, constituição.

\begin{abstract}
TThe year 2018 marked the 30th anniversary of the 1988 Federal Constitution and the re-democratization in Brazil after the Military Dictatorship. This study proposes to critically analyze the re-democratization, based on some concepts of Carl Schmitt and Giorgio Agamben, in order to show the remains of the dictatorship - via authoritarian and exceptional apparatus - within the constitutional text itself. It is not a question of minimizing the advances introduced by the new constitutional text in 1988, especially in relation to the fundamental rights and guarantees introduced, but to seriously analyze the constitutional order through the bias of the exception and the problems caused by the inscription - and permanent use - of these institutes in the legal system. Under the perspective of a critical analysis of the constitutionalism, it's adopted a method of bibliographic research and conceptual analysis, showing how the Brazilian democracy is related to the dictatorship, following the same logic of operation.
\end{abstract}

Keywords: Brazil, democracy, exception, constitution.

Articulo: Recibido el 7 de abril de 2020 y aprobado el 30 de junio de 2020

\section{Cómo citar este artículo:}

da Silva F. (2020). Dilemas da democracia brasileira: república em Estado de Exceção permanente. Reflexión política 22(45), pp. 54-69. doi: https://doi.org/10.29375/01240781.3880

\section{Considerações iniciais}

"Se fosse possível e desejável resumir em uma única fórmula o atual estado do mundo, eu não pensaria duas vezes: estado de sítio”. Com essas palavras é que Paulo Arantes (2007, p. 153) classifica o tempo presente. Mas quais os elementos para tal diagnóstico? Se de fato tem-se um estado de sítio - emergência, urgência ou exceção - permanente, o que isso significa para se pensar criticamente a sociedade democrática? A 
derrota militar do fascismo no contexto mundial não cancelou o estado de emergência de salvaguarda do capitalismo (Arantes, 2014, p. 317), cuja trajetória ascendente passou por novas calibragens e formas de adequação dentro do próprio regime democrático. O ano de 2018 foi decisivo para o Brasil: a comemoração dos 30 anos da Constituição Federal de 1988, marco da "redemocratização" após a ditadura militar, mas também com ameaças explícitas aos princípios democráticos básicos - incluindo de imprensa livre -, representadas pela ascensão da extrema-direita ao poder no Brasil por meios democráticos (Santos e Tanscheit, 2019).

Segundo Agamben (2004), historicamente a teoria do direito ignorou problemas agora enraizados nas democracias contemporâneas ocidentais: a relação intrínseca entre Estado democrático de direito e estado de exceção. Para entender a problemática de como pensar essa relação, a aparente contradição de um regime democrático que recorre a medidas antidemocráticas para se perpetuar, é oportuno retomar Carl Schmitt (1996b), precisamente porque mesmo durante a República de Weimar Schmitt entendeu a evolução do estado de exceção militar-policial ao estado de exceção econômico-financeiro, ou seja, a exceção como garantia do capitalismo. A expansão dos poderes executivos tem sido tão contínua que a emergência militar deu lugar à emergência econômica (Bercovici, 2006). Objetiva-se mostrar que o movimento autoritário e de contrarrevolução - sem, no entanto, revolução - que o Brasil vem enfrentando atualmente não é necessariamente fruto de um problema recente, que certas condições de golpe de Estado foram estruturalmente inseridas no constitucionalismo brasileiro, permitindo a ascensão do fascismo que ganhou formas de articulação dentro do próprio regime democrático.

Nesse sentido, norteia-se pelos questionamentos de se ainda podemos falar de democracia no Brasil, mais, se o que tínhamos era de fato um regime democrático ou tal fratura do presente precisamente mostrou uma realidade violenta, autoritária e antidemocrática, que já era regra nas periferias, mas que agora toma seu lugar também nos grandes centros. Tendo em vista a natureza teórica da proposta, a metodologia de pesquisa bibliográfica e análise conceitual embasará as reflexões sobre os autores, conceitos e problemas apresentados.

\section{Exceção permanente: paradigma da politica contemporânea}

A expressão "estado de exceção", conforme Agamben (2004, p. 15), aparece na doutrina jurídico-política alemã como Ausnahmezustand (estado de exceção) ou também Notstand (estado de necessidade). A tradição italiana ou francesa prefere tratar, essencialmente, de "decretos de emergência" ou de "estado de sítio" (état de siège) político ou fictício. Na terminologia anglo-saxã, utilizam-se as expressões martial law (lei marcial) e emergency powers (poderes de emergência). Aliás, essa terminologia "estado de exceção" não expressa nenhuma conexão com o estado de guerra, pelo contrário, a partir de sua criação, a história do estado de exceção é a história de sua progressiva emancipação a respeito das situações de guerra, convertendo-se em um instrumento extraordinário da função de polícia que exerce o Estado e, passo seguinte, no paradigma de governo das democracias contemporâneas (Agamben, 2004, p. 18). É no século XIX que a temática do estado de exceção ganha força no que se refere a investigações acerca do tema na teoria do direito público, ocorrendo concomitantemente o alargamento da discussão a respeito de se pensar a constitucionalização ou a regulação jurídica da exceção. Conforme Bercovici (2008, p. 216), o estado de exceção torna-se "um instrumento inseparável do Estado de Direito, que busca tornar a anormalidade uma situação constitucional”. Ao menos a partir da Primeira Guerra Mundial, a história do dispositivo da exceção mostra que seu desenvolvimento foi independente de sua formalização constitucional ou legislativa.

No caso da Alemanha, a história do artigo 48 da Constituição de Weimar está diretamente vinculada à história alemã entre guerras, sendo, para Agamben, impossível entender a ascensão de Hitler ao poder sem antes analisar os usos e abusos desse dispositivo constitucional entre os anos 1919 e 1933. Seu precedente direto é o artigo 68 da constituição Bismarckiana, prevendo que em casos da segurança 
pública estar ameaçada no território do Reich, era garantido ao imperador o poder de declarar a parte problemática do Reich em condição de conflito (estado de guerra, Kriegszustand), podendo fazer o necessário para resolver o problema. Com vistas aos casos de desordem e revoltas que se seguiram ao fim da guerra, em 1918, os membros da assembleia constituinte que iriam instituir a nova constituição, na cidade de Weimar, incluíram um artigo que garantia ao presidente do Reich poderes excepcionais de suspender direitos fundamentais garantidos pelo próprio texto constitucional. No contexto de colapso econômico e social da República de Weimar, para assegurar ou manter a lei e a ordem, o presidente do Reich poderia suspender direitos civis garantidos constitucionalmente, significa dizer, em casos excepcionais e de acordo com a circunstância, todos esses direitos fundamentais poderiam ser parcialmente ou totalmente revogados, conforme previsão do texto legal.

Para Agamben (2004), no curso do século $\mathrm{XX}$ assistimos a um fato paradoxal, ao que se denominou uma "guerra civil legal", de modo que o totalitarismo moderno poderia ser definido como a instauração dessa denominada guerra civil legal por meio do estado de exceção que, essencialmente, "permite a eliminação física não só dos adversários políticos, mas também de categorias inteiras de cidadãos que, por qualquer razão, pareçam não integráveis ao sistema político" (Agamben, 2004, p. 13). Nesse sentido, continuará Agamben apontando que todo o Terceiro Reich, a partir do denominado "Decreto para a proteção do povo e do Estado", emitido por Hitler em 28 de fevereiro de 1933, que suspendia direitos e garantias individuais previstos na Constituição de Weimar, "pode ser considerado, do ponto de vista jurídico, como um estado de exceção que durou 12 anos" (Agamben, 2004, p. 13). Desde então, a criação de um estado de emergência permanente converteu-se em uma das práticas essenciais dos Estados contemporâneos, ou melhor, em um paradigma de governo na política contemporânea, inclusive nos Estados chamados democráticos.

Diante do incessante avanço do que foi definido como uma "guerra civil mundial", o estado de exceção tende cada vez mais a se apresentar como o paradigma de governo dominante na política contemporânea. Esse deslocamento de uma medida provisória e excepcional para uma técnica de governo ameaça transformar radicalmente - e, de fato, já transformou de modo muito perceptível - a estrutura e o sentido da distinção tradicional entre os diversos tipos de constituição. O estado de exceção apresenta-se, nessa perspectiva, como um patamar de indeterminação entre democracia e absolutismo [grifo nosso] (Agamben, 2004, p. 13).

Segundo Agamben (2004), foi Carl Schmitt (1996b) quem tentou formular uma teoria mais rigorosa do estado de exceção, em Die Diktatur (A ditadura) e em Politische Theologie (Teologia política). Na primeira obra, o estado de exceção é apresentado por meio da figura da ditadura, em que Schmitt distingue entre uma "ditadura comissária", que busca defender e restaurar a ordem vigente, e a "ditadura soberana", uma figura da exceção, que não mais busca manter a ordem vigente, mas romper e "criar" uma nova constituição. Em "Teologia Política”, Schmitt (1996b, p. 92) argumenta que o estado de exceção é algo "diferente da anarquia e do caos, no sentido jurídico a ordem continua subsistindo, mesmo sem ser uma ordem jurídica". Em seguida, ressalta que, no caso da exceção, "o Estado suspende o direito em função de um, por assim dizer, direito à autopreservação" (Schmitt, 1996b, p. 92). Schmitt fundamenta que o soberano seria aquele que deteria o poder de decisão sobre o estado excepcional porque a norma em si não seria capaz de expressamente prever ou tipificar todos os casos excepcionais, por isso a necessidade de uma figura soberana que, no caso emergencial concreto, teria o poder de decisão sobre o que deveria ser feito.

O caso excepcional, aquele caso não circunscrito na ordem jurídica vigente, pode ser no máximo definido como um caso de emergência extrema, de perigo à existência do Estado ou algo assim, mas não pode ser circunscrito numa tipificação jurídica. É só esse caso que torna atual a questão do sujeito da soberania, isto é, a questão da soberania em geral. Não se pode determinar com clareza precisa quando ocorre um caso emergencial, como também não se pode enumerar o que pode ser feito nesses casos, quando se trata realmente de um caso emergencial extremo que deve ser eliminado.... No sentido do Estado de direito não há, portanto, nenhuma competência, nesse caso. A constituição, no máximo, menciona quem pode tratar da questão. Se esse tratamento não se subordinar a nenhum controle, então não 
se distribuirá (como na prática da Constituição do Estado de direito) de alguma forma entre as diversas instâncias mutuamente restritivas e balanceadoras; assim se evidenciará claramente quem é o soberano. Ele não só decide sobre a sobrevivência do Estado emergencial extremo, mas também sobre o que deve ser feito para eliminá-lo. Ele se situa externamente à ordem legal vigente, mas, mesmo assim pertence a ela, pois é competente para decidir sobre a suspensão total da Constituição. Todas as tendências do desenvolvimento do moderno Estado de direito são no sentido de eliminar o soberano.... Mas se o caso extremo de exceção realmente pode ou não ser eliminado do mundo, não é uma questão jurídica (Schmitt, 1996b, p. 88).

Qualquer que seja a terminologia dada pela literatura político-jurídica - estado de emergência, urgência, estado de sítio, etc. -, conforme o filósofo Paulo Arantes (2007), representa o regime jurídico excepcional ao qual determinada comunidade política é temporariamente submetida, "por motivo de ameaça à ordem pública, e durante o qual se conferem poderes extraordinários às autoridades governamentais, ao mesmo tempo em que se restringem ou suspendem as liberdades públicas e certas garantias constitucionais" (p. 153). Desse modo, busca-se, em certa medida, defender a ordem jurídica de alguns, ainda que seja ameaçada a vida e direitos fundamentais de outros ${ }^{1}$. Quando o estado excepcional se torna a regra, diz Agamben (2004, p. 18), "ele não só sempre se apresenta muito mais como uma técnica de governo do que como uma medida excepcional, mas também deixa aparecer sua natureza de paradigma constitutivo da ordem jurídica”. É preciso chamar a atenção para o fato de que a característica principal da exceção é que sua exclusão não a coloca necessariamente fora da relação com a norma. Pelo contrário, ela se mantém em relação à exceção justamente por meio de sua suspensão. Esse é, propriamente, o paradoxo do estado excepcional: "estar-fora e, ao mesmo tempo, pertencer: tal é a estrutura topológica do estado de exceção, e apenas porque o soberano decide sobre a exceção é, na realidade, logicamente definido por ela em seu ser" (Agamben, 2004, p. 57. Grifos no original).

Agamben (2004) chama a atenção para o fato de que o estado excepcional moderno é uma "criação da tradição democrático-revolucionária e não da tradição absolutista” (p. 16), ou melhor, trata-se de um problema genuíno das democracias contemporâneas ocidentais. A origem do moderno instituto se encontra, segundo Agamben (2004), no decreto de 8 de julho de 1791, da Assembleia Constituinte francesa; e a noção de suspensão da constituição foi primeiramente introduzida na Constituição da primeira república francesa, que continha um artigo que previa a possibilidade de declarar uma cidade ou uma região hors la constitution, fora da constituição. O problema causado na vigência do estado de exceção é a característica de "plenos poderes" que se refere à "ampliação dos poderes governamentais e, particularmente, à atribuição ao executivo do poder de promulgar decretos com força de lei" (Agamben, 2004, p. 17). As consequências no plano social podem ser drásticas e irreversíveis, pois tal prerrogativa - ou poderes excepcionais pode inclusive ser usada para conter conflitos e manifestações dentro dos limites do Estado, em nome ou sob a justificativa de manutenção da lei e da ordem. Interessante esse ponto, pois parecenos que o Estado democrático de direito mantém uma relação com o estado de exceção como que se recorresse a um medicamento, ou seja, para "sanar" eventuais situações excepcionais, toma-se - dentro dos próprios limites territoriais do país - todas as medidas necessárias para conter os possiveis distúrbios. Aliás, quando Agamben comenta a respeito do que chama de "arquétipo" do moderno Ausnahmezustand, o iustitium, um instituto do direito romano que permitia a suspensão temporária da ordem legal por intermédio de um senatus consultum ultimum, também em casos de urgência, o filósofo italiano introduz a leitura de Theodor Mommsen (citado por Agamben, 2004, p. 69) ao enfrentar a problemática do estado de necessidade

\footnotetext{
${ }^{1} \mathrm{~A}$ banalidade de tais institutos excepcionais no Brasil tomou uma proporção que resulta na constante suspensão de direitos fundamentais, algo também visível na seara criminal. No contexto do judiciário brasileiro, mais específico com o desenrolar da "Operação Lava-Jato", além de cerceamento de defesa, quebra de sigilo de interceptações telefônicas, violando sua regulamentação, uma modalidade de medida excepcional tornada regra - que foi tardiamente considerada inconstitucional pelo Supremo Tribunal Federal após várias violações de direitos - é a denominada "condução coercitiva", que só deveria ser utilizada em último caso, quando há a recusa por parte do indivíduo em comparecer em juízo, culminando não em aplicação da legislação, mas em criação da lei em movimento. O então juiz Sérgio Moro da $13^{\mathrm{a}}$ Vara Federal de Curitiba - que decidiu pela prisão do principal opositor político a Jair Bolsonaro, recebendo como troca o cargo de Ministro da Justiça, cargo este que exerceu até 24 de abril de 2020 -, responsável pelo julgamento dos processos no âmbito da Operacão Lava Jato, disse publicamente: "Claro que a prisão preventiva é excepcional, mas, infelizmente, estamos em tempos excepcionais" (artigo de Guilherme Azevedo, portal Uol. Disponível em: <https://noticias.uol.com.br/politica/ultimas-noticias/2016/10/04/estamosem-tempos-excepcionais-diz-moro-ao-defender-prisoes-preventivas.htm>.)
} 
enquanto pressuposto para a emissão do senatus consultum ultimum, recorrendo-se a um direito de legitima defesa do Estado para explicar justamente a recorrência a tais institutos: como nos casos urgentes, em que falta a proteção da comunidade, assim, "todo cidadão adquire um direito de legítima defesa, assim também existe um direito de legitima defesa para o Estado ... quando a comunidade está em perigo e a função do magistrado vem a faltar".

Ao recorrer ao arquétipo do moderno estado de exceção, Mommsen está chamando a atenção para um fato extremamente preocupante que abala os próprios princípios em que se funda a democracia contemporânea: essa, para se perpetuar, tem a necessidade -ponto centralde recorrer a eventuais medidas até mesmo antidemocráticas para conter crises internas ou externa,s tanto de cunho econômico quanto social. É justamente esse paradoxo apresentado por Agamben o que nos leva a inferir que o estado de exceção mantém relação direta com o Estado democrático de direito, no sentido de o primeiro constituir a parte da democracia que só se manifesta diante de casos que escapam à normalidade. O estado excepcional seria, no fundo, "a face oculta do estado de direito”, quer dizer que, este último possui "mecanismos ou pretende a conexão com o estado de exceção como forma de garantia de suas estruturas e em nome da manutenção da ordem e da democracia" (Ramiro, 2017, p. 27). Significa, portanto, que há sérios problemas na forma jurídica e, evidentemente, na forma do contrato enquanto justificação racional da violência estatal. Trata-se de um instituto que possibilita ao Estado o uso indiscriminado da violência para suprimir toda e qualquer excepcionalidade que eventualmente possa surgir, até mesmo de desobediência civil. Violência estatal essa que garante e mantém a vigência da Constituição ainda que em detrimento da aniquilação do divergente, do outro, do inimigo. O conceito e a imagem da democracia moderna "são profundamente intrigantes e há algo certamente enigmático quando nos aproximamos de uma análise pretensamente mais detida de seus fundamentos" (Ramiro, 2017, p. 132). Essa relação entre Estado democrático e estado de exceção, entre democracia e medidas autoritárias e antidemocráticas, coloca em evidência esse movimento pendular através do qual a exceção configura a face oculta da democracia liberal, sendo trazida à tona sempre quando convém a este sistema, não como mero mecanismo de defesa, mas, pelo contrário, como a regra.

\section{Exceção, a forma jurídica do liberalismo}

Para Agamben (2014b), o termo segurança refere-se a uma palavra cujo sentido é tão abrangente que muitas vezes não atentamos para seu significado.

Erigido como prioridade política, esse apelo à manutenção da ordem muda constantemente seu pretexto (a subversão política, o terrorismo...), mas nunca seu propósito: governar as populações. A expressão "por razões de segurança" funciona como um argumento de autoridade que, cortando qualquer discussão pela raiz, permite impor perspectivas e medidas inaceitáveis sem ela (Agamben, 2014b, par. 1).

Isso mostra o quanto a obsessão por segurança pode modificar a democracia, por intermédio de mecanismos de contenção capazes de suprimir direitos e garantias individuais. Ao passo que os procedimentos de exceção visam, em tese, uma ameaça imediata e real a ser eliminada, recorrer à proposição geral "por razões de segurança”, pelo contrário, constitui uma técnica de governo normal e permanente. Por razões de segurança econômica ou social, recorre-se constantemente a medidas de retirada de direitos e garantias fundamentais. O autor argumenta que a crescente multiplicação de dispositivos de segurança implica, não obstante, uma mudança inclusive na conceituação política, ao ponto de, nos seus termos, "podermos legitimamente nos perguntar não apenas se as sociedades em que vivemos ainda podem ser qualificadas de democráticas, mas também e acima de tudo se elas ainda podem ser consideradas sociedades políticas” (Agamben, 2014b, par. 13). Agamben está chamando a atenção de que há um sério movimento de retirada de direitos sob o fundamento de razões de segurança - sobretudo após o marco estabelecido pelo 11 de setembro de 2001 e a instauração da cultura do pânico que inaugura (Matos, 2003) -, ou melhor, há uma tendência a recorrer a essas medidas em tempos de crise ou perturbação: em tempos de instabilidade econômica, busca-se a precarização de direitos sob o fundamento de "combate" à crise. No entanto, se a crise no sistema de produção capitalista se manifesta de forma cíclica, então, consequentemente, a utilização de mecanismos excepcionais torna-se 
não mais a exceção, mas a regra. No contexto atual brasileiro tem-se a constante aplicação de medidas excepcionais inclusive no "combate" à corrupção, que não passa de um discurso retórico para galvanizar simpatias e, no passo seguinte, "arrasar com as instituições políticas de que dispomos e duramente conquistamos" (Bueno, 2017, p. 162). A partir dessas coordenadas, é possivel uma reflexão conjuntural de como a exceção vem se tornando a regra no Brasil.

O que está em curso é uma ampla insatisfação dos estratos superiores da sociedade, entre empresários e demais proprietários e operadores do capital, estimulados o suficiente para promover a derrubada do atual governo brasileiro. Quem, efetivamente, acompanha e apoia Temer em seu insano plano econômico? Quem pode no mundo moderno apoiar esta versão superada de capitalismo total para uma via fascio-pósneoliberal radical? Gual setor da população apoia a implementação de medidas altamente restritivas ainda mesmo de direitos mínimos? O capitalismo como objeto-mor e fim inatacável e inviolável sob qualquer argumento ou consequência como pode ser mantido a expensas dos homens que lhe dão real sentido? O capital concentrado de poucos pode ser adotado como paradigma para a organização humana? Tardamos e ainda não compreendemos que a economia capitalista não guarda nenhuma relação necessária com a democracia e pode conviver tranquila e levemente com um sistema político autoritário. Precisamos saber disto e agir sempre e quando é chegado o momento em que o capital deseja subordinar o mundo soberano da política, que é a única via e forma de que a democracia triunfe (Bueno, 2017, p. 162).

Em tempos de crise econômica, ocorre o que Giacoia Jr. (2017, p. 176) classifica como uma "hipertrofia (supostamente excepcional) do executivo e uma erosão do legislativo, como meio de neutralização do perigo via regulamentação, o que torna o executivo mais forte, aumentando seu poder de governo e restringindo direitos dos cidadãos". Conforme apontou Bercovici (2008), a banalidade de tais dispositivos resulta na suspensão constante de direitos fundamentais, resultando em criação da lei em movimento, algo também visível na área criminal. No contexto do judiciário brasileiro, sobretudo com o desenrolar da "Operação LavaJato" até 2016, medidas excepcionais tornaram-se a regra com o aval de instâncias judiciais superiores ${ }^{2}$. Bueno (2017) comenta:

Na esfera jurídica observamos como o Estado de exceção foi reconhecido em decisão do Tribunal Regional Federal da $4^{\underline{a}}$ Região situado na cidade de Porto Alegre, capital de Estado que já realizou movimento independentista e ergueu barricadas pela legalidade em 1961. Hoje, em tempos de homens pequenos, sucumbe ante a sua pior e mais nefasta tradição autoritária somada ao retraimento político cidadão e aos dias de crise econômica bem como à covardia estatal de enfrentá-la gravando os endinheirados, senão concentrando o ônus na população desassistida. [...] O Estado de exceção reconhecido pelo citado Tribunal funciona sob a lógica do voluntarismo e da suspensão do governo das leis, é a substituição da legalidade-legitimidade pelo recurso à negação de ambas em prol da visão messiânico-salvacionista do Estado. Esta manobra é realizada através do império da vontade de um só ou de poucos e, em qualquer caso, de um regime autoritário-elitista, do que é o exemplo o presente caso brasileiro. O reconhecimento judicial do Estado de exceção transmite uma seríssima mensagem ao conjunto dos atores jurídicos. Informa aos órgãos julgadores que podem dar azo e livre curso ao abandono, a qualquer momento, dos parâmetros legais para realizar os julgamentos (p. 169).

No estado permanente de usurpação de direitos que se pauta em fundamentos fajutos de combate às crises e manutenção de ordem de cunho econômico ou social - mais econômica que social -, é preciso ressaltar que o conceito de ordem não é um conceito neutro e, em termos operacionais, no que diz respeito a processos de tomada de decisões políticas, estabelecer os critérios e o âmbito do que pode ser considerado estado crítico - necessitando, assim, de um suposto reestabelecimento da ordem via medidas de exceção -, envolvem-se diretamente escolhas que refletem as estruturas política e

${ }^{2} \mathrm{Em}$ decisão na qual advogados apontavam que as investigações ignoravam os limites da lei, por exemplo, ao permitir grampos em escritório de advocacia, divulgação de interceptações telefônicas envolvendo a Ex-Presidente da República e assim por diante, para o Tribunal Regional Federal da $4^{a}$ Região, os processos trazem problemas inéditos e exigem soluções "inéditas". Os desembargadores, por 13 votos a 1, reiteraram as ações do então juiz Sérgio Moro que firmam o estado de excecão como regra. Diz parte do voto do relator: "Ora, é sabido que os processos e investigações criminais decorrentes da chamada 'Operacão Lava-Jato', sob a direção do magistrado representado [Sérgio Moro], constituem caso inédito (único, excepcional) no direito brasileiro. Em tais condições, neles haverá situações inéditas, que escaparão ao regramento genérico, destinado aos casos comuns". Ou seja, em tempos de anormalidade, suspende-se o direito "normal", dando primazia a um direito de exceção. 
ideológica dominantes, qual seja, de garantia do modo de produção capitalista e sistema econômicopolítico neoliberal. O estado de necessidade, longe de apresentar-se como um dado objetivo, implica, ao contrário, juízos subjetivos relativos ao propósito que se quer atingir. Em termos de uma tradição dos oprimidos, esse estado de exceção econômico é e sempre foi, na verdade, a regra, por isso a partir do questionamento trazido acima por Bueno (2017) ao indagar sobre quem em sã consciência poderia apoiar essa versão selvagem de capitalismo total nos leva a argumentar que, no fundo, essa é e sempre foi a regra. Não há espaço para espanto, pois o lucro está, nessa concepção de mundo, acima de quaisquer eventuais questões humanitárias. O capital, para se manter e se firmar, necessita desses mecanismos.

O capital tem em seu horizonte a máxima realização do lucro e, além disto, apenas considera a instrumentalização de meios, e para tanto nenhum problema supõe a restrição de direitos e garantias públicas ou de direitos sociais. Não sobrevive neste terreno qualquer preocupação com a realização da igualdade de oportunidades, e este pode ser compreendido como o resumo da despreocupação da economia capitalista com a realização da justiça social, o indiferentismo cru com a perspectiva do humano (Bueno, 2017, p. 163).

Bercovici (2008, p. 46) também busca argumentar que a evolução do fato de empregar constantemente medidas excepcionais no decorrer do século XX vai da "violência aberta, como o fascismo, à sutil e recente elaboração de uma constituição desvinculada do Estado e do poder constituinte do povo, mas instituidora e garantidora da ordem do mercado”. Com um estado de exceção econômico e social permanente, convívio rotineiro com o impacto do decisionismo de emergência na subordinação do Estado ao mercado, temse a adaptação do sistema jurídico e político às necessidades do capital financeiro, exigindo cada vez mais flexibilidade para reduzir as possibilidades de interferência da soberania popular. Assim, mais do que o argumento da garantia ou prolongamento da vida do regime político, o estado de exceção passou a ser empregado não só na garantia da constituição, mas consolida-se como modelo de garantia do capitalismo (Bercovici, 2008). Conforme Bueno (2017), o poder estabelecido não mais disfarça seus atos de força e violência, tal como ocorreu na ordem de cercamento do Congresso Nacional, no dia 9 de maio de 2017, para que assim fossem analisados os destaques da reforma da Previdência - e mais uma vez surge o caráter reformista enquanto medida excepcional necessária para que o "sistema" continue a funcionar, legitimando a usurpação de direitos dos que pouco ou nada têm na manutenção do sistema econômico-financeiro -, "em uma clara demonstração de que ali se faria a impostura de votação legal, posto que a população brasileira a ela se opõe em sua quase totalidade segundo indicam os dados levantados pela imprensa" (Bueno, 2017, p. 168).

Oliberalismonunca precisou dademocracia, pelo contrário, sua lógica de funcionamento tem estado alinhada com o de regimes ditatoriais e autoritários, vide enriquecimento de empresas que se alinharam à Ditadura Militar brasileira, no qual "funcionavam normalmente encharcadas do sangue de torturados escorrendo pelo chão dos sótãos e das salas fechadas de cujas portas muitos empresários tinham a chave" (Bueno, 2017, p. 163). Para justificar as aspirações de subversão da ordem e manutenção do capital, as elites do capitalismo predatório brasileiro "precisam de uma densa cortina de fumaça e, assim, criam artificialmente uma situação de crise extrema" (Bueno, 2017, p. 168), inclusive - e especialmente - via grande mídia, visto que será com seu apoio que "quadrilhas assaltantes do poder e da riqueza nacional podem falsificar a narrativa do real, que terão êxito em redescrever falsamente as estruturas e influenciarão potentemente na percepção pública da realidade" (Bueno, 2017, p. 168), algo também perceptivel com as fake news ${ }^{3}$.

Miguel Reale (1986), jurista de direita que participou ativamente da Comissão de Estudos Constitucionais, tenta demonstrar que é equivocado falar em autoritarismo, afirmando que o texto constitucional brasileiro tratava acertadamente em estado de emergência e estado de sítio, designações que deviam ser mantidas no texto constitucional

${ }^{3} \mathrm{O}$ presidente norte-americano, Donald Trump, costuma se referir às fake news como alternative facts, fatos alternativos. Trata-se de uma relativização à verdade, tratando o falso como "verdade alternativa". No Brasil, o uso de fake news tem se tornado cada vez mais frequente, sobretudo por governantes e apoiadores de extrema-direita. 
de 1988, sustentando a interpretação de que esses mecanismos excepcionais se justificariam na medida em que seriam utilizados na manutenção e autodefesa da democracia. Segundo sua leitura, a existência de "instrumentos de preservação da ordem democrática, longe de resultar de um neoautoritarismo, visa antes a reduzir o emprego de amplos poderes discriminatórios" (Reale, 1986, par. 4), em que dada a composição democrática do Congresso Nacional, estaria afastada a hipótese do uso de poderes de exceção sem justa causa. Passando em análise de textos constitucionais de países democráticos e utilizando-os como exemplo, Reale, valendo-se de argumento de autoridade, conclui sua intervenção apontando que "nada há de criticável e muito menos de malicioso nas soluções aprovadas por nossa Comissão, que não compartilha de iluminismo acalentado por aqueles que sonham com um paraíso democrático só composto de amantes da lei e da paz" (Reale, 1986, par. 10). Nessa linha, seguindo a interpretação apresentada por Ramiro (2016), a posição destacada por Reale seria que a constitucionalização ou previsão da exceção se dá pela pretensão de durabilidade do Estado de Direito burguês. Conforme diagnóstico de Paulo Arantes (2007, p. 157), é como se "a forte energia liberal do governo - a um tempo tirânico e barato - nada mais fosse do que estado de sítio represado". Mais ainda, ao comentar sobre o estado de exceção permanente no qual se formou e produziu a periferia colonial e pós-colonial brasileira, o filósofo brasileiro argumenta:

Às classes confortáveis do núcleo orgânico correspondiam, como um complemento exato, as classes torturáveis nas zonas periféricas do sistema. Em tempo: na literatura especializada, e chocada, com esse paradoxo brasileiro que vem a ser a explosão exponencial da violência à medida que se consolida a "democratização" da sociedade, observa-se que as classes torturáveis são compostas especificamente de presos comuns, pobres e negros, torturáveis obviamente nas delegacias de polícia e prisões, rotina invisível que o escândalo da ditadura militar recalcou ainda mais, por ser inadmissivel torturar brancos de classe média (Arantes, 2007, p. 163).

Voltando ao ponto da exceção como regra, no Brasil, é um fato que há muito tempo configura a realidade, em especial nos espaços periféricos, porém só ganha real atenção da classe média quando, "de tempos em tempos, ele ressurge e transcende a realidade das periferias e passa a influenciar o cotidiano da classe média" (Bueno, 2017, pp. 171-172). Contrapondo à normalidade do centro, a periferia vive em um estado de exceção econômico e social permanente. Nesses espaços há o convívio rotineiro e o impacto do decisionismo de emergência para salvar os mercados com o funcionamento dos poderes constitucionais, bem como a "subordinação do Estado ao mercado, com a adaptação do direito interno às necessidades do capital financeiro, exigindo cada vez mais flexibilidade para reduzir as possibilidades de interferência da soberania popular" (Bercovici, 2006, p. 96).

A razão de mercado passa a ser a nova razão de Estado: conforme diagnóstico de Arantes (2014), a derrota militar do fascismo não cancelou o estado de emergência de salvaguarda do capitalismo, "cuja trajetória ascendente passou por uma nova calibragem, como atesta o consenso subsequente em torno das políticas keynesianas de ajuste e contenção" (p. 317). Assim, mais do que interferir nas liberdades políticas, limitando direitos individuais, a utilização atual de poderes emergenciais caracteriza-se, segundo Bercovici (2006, p. 97), “por limitar os direitos da população em geral para garantir a propriedade privada e a acumulação capitalista”, é em razão disso a referência inicial do estado de exceção militar-policial ao econômicofinanceiro. Toda a bibliografia sobre o estado de exceção caminha no sentido de mostrar que com a nova geopolítica monetária e a concentração dos centros de decisão sobre investimentos (que leva à possibilidade de retaliação econômica como o fundamento último da soberania no que diz respeito às políticas econômicas dos Estados periféricos), aliado à instabilidade econômica, aumentouse a recorrência aos poderes emergenciais para sanar crises econômicas e, não obstante, o antigo Ausnahmezustand se espalhou por toda a parte, tornando-se o estado de emergência econômico estrutura jurídico-política permanente e global.

\section{A exceção brasileira, ontem e hoje}

Um ponto fulcral no texto constitucional brasileiro diz respeito à possibilidade de o Executivo recorrer a Medidas Provisórias com força de lei, forçando o Legislativo a se manifestar sobre o tema tratado num prazo máximo de sessenta dias. Ainda que existam matérias que não poderiam ser tratadas mediante 
tais medidas emitidas pelo Executivo, assim como os Decretos, trata-se de um dispositivo cujo arquétipo está diretamente relacionado com a recorrência constante a mecanismos excepcionais por parte do Executivo, configurando o que Agamben atribui como o paradigma da política contemporânea. Após tratado sobre a intrínseca relação do Estado democrático de direito e o estado de exceção, e sobre a exceção enquanto instrumento de manutenção do sistema econômico capitalista, sob as bases conceituais introduzidas por Schmitt e Agamben, é importante fazer essa aproximação conceitual ao ordenamento jurídico brasileiro, analisando alguns institutos constitucionais da Constituição Federal de 1988, objetivando-se, conforme sugere Ramiro (2016, p. 221), "uma leitura da ordem constitucional levando em consideração a questão sobre o que resta da ditadura brasileira, tendo em vista a hipótese do filósofo italiano a respeito da solidariedade entre democracia e totalitarismo". Uma vez que o vínculo entre Estado democrático de direito e estado excepcional é, segundo Ramiro (2016, p. 223), "garantido e operacionalizado pela forma jurídica”, faz-se necessário retomar o ponto já discutido anteriormente acerca da inclusão ou previsão da exceção no ordenamento jurídico brasileiro, tendo em vista que "a constituição liberal tem dificuldades [...] de enquadrar o estado de exceção, que intencionalmente é excluído dos textos constitucionais" (Bercovici, 2008, p. 216).

Conforme Bercovici (2008, p. 217), o estado excepcional transforma-se em estado de sítio ou necessidade como "solução encontrada pelo Estado de Direito burguês para o estado de exceção. É o instituto típico ejurídico desta forma de estado". Mais ainda, segundo Canotilho (1998, p. 961), trata-se de "submeter as situações de crise e de emergência (guerra, tumultos, calamidades públicas) à própria Constituição, 'constitucionalizando' o recurso aos meios excepcionais, necessários, adequados e proporcionais", com a finalidade de obter o reestabelecimento do que o autor chama de "normalidade constitucional". Schmitt já havia destacado sobre o caráter abrangente da norma jurídica e a impossibilidade da tentativa de abarcar todos os casos situacionais, mas o que nos interessa é a análise do constitucionalismo brasileiro, apesar da ressalva de Bercovici (2008) que, na América
Latina, a primeira constituição a prever o estado de sítio foi a chilena de 1833, com vigência até 1925. Ao pensar na chave da história do constitucionalismo brasileiro, Ramiro (2016, pp. 225-226) argumenta que "pode-se verificar certa tendência em reconhecer ou conceber um poder executivo forte, com autoridades expressivas" dentro das constituições outorgadas ou promulgadas desde 1824 a 1988, e que mesmo durante a vigência da Constituição de 1891, "o abuso da utilização (e prorrogação) do estado de sítio pelos sucessivos presidentes da república foi a regra” (Bercovici, 2008, p. 224), mesmo durante a primeira república o estado de exceção foi um fenômeno no regime presidencialista brasileiro.

Durante o desenvolvimento constitucional do país, pelo menos de 1891 até hoje, é possível notar a presença do Brasil na tradição de países que pretendem inscrever a exceção no ordenamento jurídico, com a justificativa de poder constitucionaliza-lo para limitar a sua utilização, que deve ser feita com o objetivo precípuo de garantia da ordem e segurança públicas, na maior parte dos casos (Ramiro, 2016, p. 226).

Apesar da importância na reconstrução da história do constitucionalismo brasileiro, o recorte histórico pretendido retém-se ao período pós1964, com a tomada do poder pelo golpe militar, período que antecede a nova ordem democrática introduzida pelo texto constitucional de 1988 (Ramiro, 2016), fruto de um acordo que será melhor analisado posteriormente. Nesse contexto, Bonavides e Andrade (1991, p. 429), ao comentar sobre os chamados Atos Institucionais e sobre as Emendas constitucionais, ressaltam que "o período de abril de 64 a dezembro de 66 registra [...] a edição de quatro atos institucionais e quinze emendas constitucionais", sendo estes atos reconhecidos, segundo Ramiro (2016, p. 227), como "próprios aos de um estado de exceção". Apesar da preocupação, por assim dizer, por parte dos que orquestraram o golpe militar - ou, nos termos do AI-1, dos que perpetraram a "revolução vitoriosa" ${ }^{-}$, de constitucionalizar o regime ditatorial inaugurado, "essa preocupação não nos impede de constatar que a verdadeira Constituição daqueles anos foram

${ }^{4}$ Dirigido à nação, segue trecho parcial do preâmbulo do Al-1: "É indispensável fixar o conceito do movimento civil e militar que acaba de abrir ao Brasil uma nova perspectiva sobre o seu futuro. O que houve e continuará a haver neste momento, não só no espírito e no comportamento das classes armadas, como na opinião pública nacional, é uma autêntica revolução. A revolução se distingue de outros movimentos armados pelo fato de que nela se traduz, não o interesse e a vontade de um grupo, mas o interesse e a vontade da Nação. A revolução vitoriosa se investe no exercício do Poder 
os atos institucionais" (Bonavides e Andrade, 1991, p. 430). Nessa linha interpretativa, continuam os autores:

O Ato Institucional $\mathrm{n}^{\mathrm{o}} 1$ incorporou o decurso de prazo; a suspensão das garantias constitucionais ou legais de vitaliciedade e estabilidade, o direito de suspender os direitos políticos pelo prazo de dez anos e cassar mandatos legislativos federais, estaduais e municipais, excluída a sua apreciação judicial. O AI-2 extingue os partidos políticos; dá ao Presidente da República o direito de baixar atos complementares, bem como decretos-leis sobre matéria de segurança nacional (expressão vaga e elástica que podia significar qualquer coisa), dá a ele o direito de decretar o recesso do Congresso Nacional, das assembleias legislativas e das câmaras de vereadores, em estado de sítio ou fora dele. Estabeleceu, ainda, que "decretado o recesso parlamentar, o Poder Executivo correspondente fica autorizado a legislar mediante decretos-leis, em todas as matérias previstas na Constituição e na lei orgânica”. O AI-3 estende o princípio da eleição indireta do Presidente e o Vice-Presidente (estabelecido no AI2) para a eleição de governadores e vice-governadores. O AI-4 convoca o Congresso Nacional a reunir-se extraordinariamente para discutir e votar um novo texto constitucional. Diga-se, de passagem, que o ato fixava um cronograma tão rígido para a apresentação, discussão e promulgação do texto que mais parecia tratar-se da abertura de uma nova estrada rodoviária ou da construção de mais uma ponte. [...] O AI-5 englobava todos os itens constantes dos atos anteriores, acrescentando a faculdade de intervir em estados e municípios, detalhando as consequências imputáveis aos que tivessem seus direitos políticos cassados, suspendendo a garantia de habeas corpus e concedendo total arbitrio ao Presidente da República no que se refere à decretação do estado de sítio ou de sua prorrogação [grifo nosso] (Bonavides e Andrade, 1991, p. 430).

Tanto na constituição de 1967 quanto no AI-5 - ato que investiu o Estado da prerrogativa de manipulação dos corpos e da vida dos cidadãos (Teles, 2015) e resultou no fechamento do Congresso, inaugurando um dos periodos mais autoritários da história do Brasil (Zaverucha, 2010) - o estado de exceção estava devidamente previsto na emenda constitucional $\mathrm{n}^{-} \mathbf{1}$, de 17 de outubro de 1969, com a distinção entre estado de sítio e estado de defesa, dedicando um capítulo inteiro ao estado de sítio $^{5}$, que prescinde justamente o título III, que diz respeito à ordem econômica e social, algo que será importante ao analisar possiveis resquícios na Constituição Federal de 1988, além de constituir um elemento importante para se pensar na possibilidade de utilização de mecanismos excepcionais durante período de crises econômicas. É preciso ressaltar que não se trata de minimizar os avanços introduzidos pelo novo texto constitucional em 1988 no que tange a direitos e garantias fundamentais, mas a partir dos conceitos mobilizados, busca-se analisar seriamente "a nossa ordem constitucional pelo viés da exceção e dos problemas ocasionados pela inscrição desta no sistema de direitos, com isso, coloca-nos a perspectiva de uma análise crítica da Constituição e do constitucionalismo" (Ramiro, 2016, p. 229). Ramiro chama a atenção para o movimento no qual o estado de exceção foi incorporado pelo texto constitucional vigente, a imersão de elementos autoritários na transição negociada do regime autoritário para o Estado democrático de direito. Apesar de parte do texto constitucional descentralizar poderes e estipular

Constituinte. Este se manifesta pela eleição popular ou pela revolução. Esta é a forma mais expressiva e mais radical do Poder Constituinte. Assim, a revolução vitoriosa, como Poder Constituinte, se legitima por si mesma. Ela destitui o governo anterior e tem a capacidade de constituir o novo governo. Nela şe contém a força normativa, inerente ao Poder Constituinte. Ela edita normas jurídicas sem que nisto seja limitada pela normatividade anterior à sua vitória. Os Chefes da revolução vitoriosa, graças à ação das Forças Armadas e ao apoio inequívoco da Nação, representam o Povo e em seu nome exercem o Poder Constituinte, de que o Povo é o único titular. O Áto Institucional que é hoje editado pelos Comandantes-em-Chefe do Exército, da Marinha e da Aeronáutica, em nome da revolução que se tornou vitoriosa com o apoio da Nação na sua quase totalidade, se destina a assegurar ao novo governo a ser instituído, os meios indispensáveis à obra de reconstrução econômica, financeira, política e moral do Brasil, de maneira a poder enfrentar, de modo direto e imediato, os graves e urgentes problemas de que depende a restauração da ordem interna e do prestígio internacional da nossa Pátria. A revolução vitoriosa necessita de se institucionalizar e se apressa pela sua institucionalizacão a limitar os plenos poderes de que efetivamente dispõe. $\mathrm{O}$ presente Ato institucional só poderia ser editado pela revolução vitoriosa, representada pelos Comandos em Chefe das três Armas que respondem, no momento, pela realização dos objetivos revolucionários, cuja frustração estão decididas a impedir. Os processos constitucionais não funcionaram para destituir o governo, que deliberadamente se dispunha a bolchevizar o País. Destituído pela revolução, só a esta cabe ditar as normas e os processos de constituição do novo governo e atribuir-lhe os poderes ou os instrumentos jurídicos que lhe assegurem o exercício do Poder no exclusivo interesse do País. Para demonstrar que não pretendemos radicalizar o processo revolucionário, decidimos manter a Constituição de 1946, limitando-nos a modificá-la, apenas, na parte relativa aos poderes do Presidente da República, a fim de que este possa cumprir a missão de restaurar no Brasil a ordem econômica e financeira e tomar as urgentes medidas destinadas a drenar o bolsão comunista, cuja purulência já se havia infiltrado não só na cúpula do governo como nas suas dependências administrativas" Inserir autor ou título do texto <http://www.planalto.gov.br/ccivil 03/ait/ait-01-64.htm>.

${ }^{5} \mathrm{~A}$ decisão pela decretação desse estado paira ao Presidente da República em casos de guerra ou de "grave perturbação da ordem ou ameaça de sua irrupção", ou seja extremamente geral e centralizadora ficando à mercê da decisão do soberano. Aliás, a abrangência do poder decisório está prevista no $\S 2^{\circ}$, do art. 155 do texto legal, que elencava e autorizava as seguintes medidas coercitivas possíveis durante sua vigência: "a) obrigação de residência em localidade determinada; b) detenção em edifícios não destinados aos réus de crimes comuns; c) busca e apreensão em domicílio; d) suspensão da liberdade de reunião e de associação; e) censura da correspondência, da imprensa, das telecomunicações e diversões públicas; e f) uso ou ocupação temporária de bens das autarquias, emprêsa públicas, sociedades de economia mista ou concessionárias de serviços públicos, assim como a suspensão do exercício de cargo, função ou emprêgo nas mesmas entidades". <http://www.planalto.gov.br/ccivil 03/Constituicao/Emendas/Emc anterior1988/emc01-69.htm>. 
importantes benefícios sociais, conforme Zaverucha (2010, p. 45), "parte da Constituição permaneceu praticamente idêntica à Constituição autoritária de 1967 e à sua emenda de 1969. Refiro-me às cláusulas relacionadas com as Forças Armadas, Polícias Militares estaduais, sistema judiciário militar e de segurança pública em geral".

Com relação à atuação do então deputado federal, Ricardo Fiúza, um dos líderes da coalizão conservadora da Constituinte, na Subcomissão de Defesa do Estado, da Sociedade e de sua Segurança, Zaverucha (2010, p. 46) comenta que "Fiúza optou por favorecer a autonomia das Forças Armadas", ao invés de separar as forças responsáveis pela manutenção da ordem interna da externa e de fazer valer o preceito de que, em tempo de paz, as tropas militares federais deveriam ser forças de reserva das Polícias e de que o inverso só seria válido em tempo de guerra. Se lembrarmos do paradoxo da soberania - de que o soberano estaria ao mesmo tempo dentro e fora do ordenamento jurídico, o soberano, tendo o poder legal de suspender a validade da lei, colocase legalmente fora lei (Agamben, 2004) - e traçando um paralelo com os questionamentos aqui tratados, Zaverucha (2010) pergunta-se como seria possivel, logicamente, as Forças Armadas se submeterem e garantirem algo simultaneamente?

Lógica à parte, são os militares que têm o poder constitucional de garantir o funcionamento do Executivo, Legislativo e Judiciário, a lei e a ordem quando deveria ser o reverso. Ou seja, as Forças Armadas são baluartes da lei e da ordem definidas por elas mesmas [...]. Portanto, cabe às Forças Armadas o poder soberano e constitucional de suspender a validade do ordenamento jurídico, colocandose legalmente fora da lei. [...] Em uma democracia, o poder não é deferido a quem tem força, mas, ao contrário, a força é colocada ao serviço do poder. No Brasil, estabeleceu-se uma Constituição e foi entregue, precisamente, aos que são mais tentados a violá-la, a tarefa de manter a sua supremacia [grifo nosso] (Zaverucha, 2010, p. 48).

Ora, o debate é tão sério que Paulo Arantes (2010), comentando sobre a leitura de Zaverucha no que concerne às cláusulas relacionadas às Forças Armadas, polícias militares e à segurança pública em geral, diz que "a Carta outorgada pela ditadura em 1967, bem como sua emenda de 1969, simplesmente continua em vigor [grifo nosso]" (Arantes, 2010, p. 212). A Constituição Federal de
1988 concedeu particular atenção e poder às Forças Armadas, entregando-a a tarefa de garantia da lei e da ordem, visivel no artigo 142 do texto constitucional brasileiro. Ao comentar sobre o que poderia restar da ditadura, Arantes (2010), problematizando o dispositivo citado, pontualmente argumenta que, no fundo, houve uma "constitucionalização do golpe de Estado, desde que liderado pelas Forças Armadas, que passaram a deter o poder soberano de se colocar legalmente fora da lei [grifo nosso]" (pp. 212-213). Quase nos mesmos moldes no artigo 48 da Constituição de Weimar, esses dispositivos que preveem a instauração do Estado de Defesa e o Estado de Sítio, positivados nos artigos 136 a 141, evidenciam a fragilidade de se tentar positivar a possibilidade de recorrer ao estado excepcional e o que resta da ditadura no ordenamento jurídico brasileiro. Sinteticamente, o que difere o estado de defesa do estado de sítio é que, no primeiro, o Presidente da República decreta, e, no segundo, solicita ao Congresso Nacional autorização para decretar o estado de sítio. A rigor, trata-se de dispositivos que visam a estabilização e a defesa da Constituição contra processos violentos de mudança ou perturbação da ordem constitucional, mas também à defesa do Estado quando a situação crítica derive de guerra externa, momento em que a legalidade "normal" é substituída por uma legalidade extraordinária. Apesar de supostamente o estado excepcional ser decretado como último recurso mediante extrema necessidade, Silva (2009, p. 762. Grifo no original) faz a ressalva de que "o estado de exceção configurará puro golpe de estado, simples arbítrio; sem atenção ao princípio da temporariedade, sem que se fixe tempo limitado para vigência da legalidade extraordinária, o estado de exceção não passará de ditadura”. Aqui se insere inclusive a discussão - já antecipada por Schmitt - sobre quem deveria ser o guardião da ordem constitucional contra as investidas dos próprios detentores do poder, tendo em vista que o rompimento do equilíbrio constitucional surge justamente de um órgão próprio da Constituição. Para Silva (2009), o perigo se encontra nessa possibilidade de instaurar o estado excepcional, porque é "dele que provém, quase sempre, o maior perigo, ao lado das graves insurreições de militares golpistas" (p. 762). Nesses casos, "os estados de exceção visam especialmente criar condições para a implantação de ditaduras, antes que para defender 
a Constituição. Quase sempre o estado de exceção funciona como instrumento de preservação do domínio de uma classe dominante” (Silva, 2009, p. 762). Portanto, em nome da garantia da lei e da ordem, ou, se preferirmos, quando o ordenamento encontra-se ameaçado, recorre a um dispositivo que prevê medidas excepcionais justamente para preservá-lo. Ora, isso é no mínimo curioso, visto que para garantir a vigência da constituição, recorre-se a um dispositivo que justamente faz com que ela seja - de forma total ou parcial - temporariamente suspensa. Comentando sobre o estado de exceção na democracia brasileira, Teles argumenta:

Se, eventualmente, a ordem sofrer alterações ou perturbações, caberá ao soberano o julgamento sobre as condições de anormalidade. Consequentemente, também nas mãos dele estará a decisão sobre o Estado de exceção, definindo aquilo que se exclui do ordenamento por um mecanismo interno à própria política: a necessidade de manutenção da ordem. As normas se relacionam com a exceção por meio de sua própria suspensão, de modo que o excluído se inclui na ordem interrompida, adiada para outro momento. Não esqueçamos a promessa do golpe de 1964: o restabelecimento da ordem, por meio de uma nova norma, em movimento caracterizado como provisório por seus autores. Ao tomar o Estado, os militares passaram a representantes da sociedade, identificando o governo com a vontade geral, expressa pelo signo da Doutrina de Segurança Nacional e do Estado de exceção [grifo nosso] (Teles, 2010, p. 303).

A figura da exceção surge, conforme Teles, como meio de garantia da lei e da ordem via institutos que possibilita ao Estado o uso indiscriminado da violência para suprimir movimentos de desobediência, ou, mais ainda, para reprimir inclusive movimentos de resistência dentro dos limites do Estado, que garante a vigência da Constituição ainda que em detrimento da aniquilação do divergente. É precisamente nesse sentido que se faz necessário uma postura crítica, apesar dos avanços em matéria de direitos e garantias fundamentais, ao resquício autoritário que há na Constituição Federal de 1988, bem como a fragilidade dos institutos de uma constituição que foi fruto de um acordo civil-militar, não propriamente fruto de um ato de ruptura violenta, conforme lembra Ramiro (2016). O arquétipo de tais dispositivos de exceção está diretamente relacionado à recorrência constante a mecanismos excepcionais por parte do Executivo. Aliás, segundo Agamben (2004), o ponto que merece atenção é que o resultado do uso exacerbado de tais medidas provisórias pelo Executivo coloca em xeque a divisão entre os poderes, uma vez que o Legislativo tornase mero apêndice do primeiro, isto é, acaba por somente reiterar o "legislado" pelo Poder Executivo ${ }^{6}$. Quer dizer, portanto, que quando a exceção tende a tornar-se a regra, o princípio democrático de separação dos poderes sofre sérios abalos e que o poder Executivo absorveu, ao menos em parte, o poder Legislativo. No fundo, o parlamento - ou o Congresso Nacional - não mais seria o corpo legislativo soberano que detém o poder exclusivo de vincular os cidadãos na produção da legislação, mas limita-se a ratificar os decretos emitidos pelo poder Executivo. Ao pensar a democracia no mundo de hoje, poder-se-ia questionar sobre que regime é este que necessita da exceção para se perpetuar. Certamente Bercovici (2008, p. 328) tem razão quando estabelece que a "política de exceção permanente destrói o regime constitucional. O estado de exceção não está mais a serviço da normalidade, mas a normalidade a serviço da exceção". No fundo, em termos de uma sociedade aberta democrática, e olhando para a realidade brasileira, ao afastar o povo das decisões, do espaço de aprimoramento do discurso, dos espaços de debate propriamente - vide minorias sem representatividade alguma e sem espaço de fala - não se pode falar mais em democracia. Como apontado por Bueno,

O Estado de exceção é hoje uma triste realidade, pois o povo foi afastado do processo de tomada de decisões e as normas jurídicas que deveriam sustentar a pauta de decisões e as normas jurídicas que deveriam sustentar a pauta dos processos políticos e judiciais deixaram de fazê-lo, substituídas pelo puro voluntarismo de uma oligarquia ilegítima. O Brasil hoje experimenta momento histórico em que a condução da vida pública desconhece a necessária submissão ao direito e nem atenta aos diversos sinais da população, e isto, embora não declarado, apenas pode ser classificado politicamente como Estado de exceção (Bueno, 2017, p. 172).

${ }^{6}$ Nesse ponto, chamo a atenção para a Medida Provisória (MP) $n^{\circ} 746 / 2016$, que instituiu a reforma do ensino médio cujo impacto incide diretamente, dentre outros, no ensino da Filosofia no nível médio. 
O estado de exceção desvela, coloca em evidência problemas sérios que envolvem a forma jurídica. Talvez nos caiba a difícil e indeclinável tarefa de uma profanação do direito, tornando-o inoperante, para renovar os quadros conceituais da política e liberá-la de "seu confisco no interior dos limites fixados pela organização jurídica do Estado" (Giacoia Jr., 2008, p. 44). Em contraposição às coisas pertencentes ou acessiveis tão-somente aos deuses, fala-se em profanação do direito - ou até mesmo em profanação da democracia - no sentido de devolvê-la a um uso comum a todos (Agamben, 2004). Segundo Giacoia Jr. (2008, p. 45), em concordância com Agamben, essa desativação ou deposição pode ser obtida "por meio do brincar, da dissolução da seriedade e gravidade da política jurídico-estatal por meio de jogos diversos - jogo de mobilização e ação (ludus) e jogo discursivo, de palavras (jocus)" ${ }^{\prime}$. Então, apostar em uma salvação - para usar um termo messiânico (tal como aposta de parte da sociedade brasileira em figuras autoritárias que se apresentam como "salvadores da pátria”) - que vem via forma jurídica não será possivel. Só através da deposição ou supressão da forma jurídica enquanto dispositivo de captura da mera vida é que nos livraremos das correntes de dominação dos corpos.

\section{Considerações finais}

Em tempos de crise ou instabilidade econômica e/ ou social, os direitos fundamentais e as garantias mínimas dos cidadãos são suspensos sob a justificativa de "combate à crise", por isso desde o golpe de 2016 a um governo democraticamente eleito alguns políticos brasileiros vêm realizando reformas e outros projetos que minam ou acentuam a desigualdade social. O caráter reformista surge como uma medida excepcional necessária para o "sistema" continuar funcionando, mas o ponto é que o conceito de "crise" - usado por lideranças políticas para justificar a usurpação de direitos - não é algo aleatório, neutro, mas é pensado e usado pelo Estado para legitimar os interesses do mercado financeiro, neutralizando o conflito por meio de uma ala armada, impedindo a população de se voltar contra os atos do Estado e mantendo privilégios, abusos e desigualdade social.

À medida que a crise no sistema capitalista se manifesta de forma cíclica, torna-se habitual o uso de mecanismos excepcionais, com a banalização de institutos excepcionais, no qual os princípios democráticos se aplicam apenas formalmente, mas na prática são constantemente violados ou suspensos. Trata-se de um estado permanente de usurpação de direitos que se baseia em falsos argumentos de combate às crises e manutenção da ordem econômica.

O conceito de ordem também não é neutro, significa, com relação aos processos políticos de tomada de decisão, estabelecer os critérios e o escopo do que pode ser considerado um estado crítico, necessitando de um suposto restabelecimento da ordem com medidas excepcionais. Envolve diretamente escolhas que refletem as estruturas políticas e ideológicas dominantes, ou seja, a garantia desse sistema político-econômico neoliberal.

O projeto do atual governo de Jair Bolsonaro é destruir, não construir, e sempre foram claros no que concerne a esse ponto: procuram desconstruir o mínimo de socialdemocracia que o Brasil buscava como país. É um projeto neoliberal de destruição total do público, por isso fala-se em um horizonte de expectativas decrescentes (Arantes, 2014), de anulação total das expectativas com relação ao futuro: desde o golpe que afastou a ex-presidente Dilma Rousseff em 2016, alguns filósofos brasileiros falam de uma "contrarrevolução sem revolução". Bolsonaro governa através do caos, pois o caos é uma ferramenta política, por isso diariamente há um escândalo diferente. O decisionismo schmittiano, a definição de soberania como a capacidade do soberano de decidir pela suspensão da lei usando quaisquer meios para garantir a sobrevivência da comunidade, agora toma novas formas, ou seja, não é mais o regime legal excepcional ao qual uma comunidade política está temporariamente sujeita devido a ameaças à ordem e segurança públicas, durante a qual poderes extraordinários são conferidos às autoridades governamentais ao

${ }^{7}$ Sobre isso, diz Agamben (2004, p. 98): "Um dia, a humanidade brincará com o direito, como as crianças brincam com os objetos fora de uso, não para devolvê-los a seu uso canônico e, sim, para libertá-los definitivamente dele. O que se encontra depois do direito não é um valor de uso mais próprio e original e que precederia o direito, mas um novo uso, que só nasce depois dele. Também o uso, que se contaminou com o direito, deve ser libertado de seu próprio valor. Essa libertação é a tarefa do estudo, ou do jogo. E esse jogo estudioso é a passagem que permite ter acesso àquela justiça que um fragmento póstumo de Benjamin define como um estado do mundo em que este aparece como um bem absolutamente não passível de ser apropriado ou submetido à ordem jurídica". 
restringir ou suspender as liberdades públicas e certas garantias constitucionais: o caos é constante; república em estado de exceção permanente. Todos os dias há casos excepcionais diferentes para fundamentar medidas excepcionais.

O poder executivo de Bolsonaro absorveu, ao menos em parte, o poder legislativo. Basicamente, o parlamento (Congresso Nacional) não seria mais o órgão legislativo soberano que tem o poder exclusivo devincular os cidadãos à produção dalegislação, mas apenas ratifica alguns decretos emitidos pelo poder executivo. Retomo os questionamentos iniciais: o que isso significa para a democracia brasileira? Ainda pode se falar em democracia no Brasil? O permanente estado de exceção está corroendo o regime constitucional brasileiro, a exceção não está mais a serviço da normalidade, mas a normalidade a serviço da exceção, é por isso que Agamben (2004) argumenta que a criação voluntária de um estado permanente de emergência (embora talvez não declarado no sentido técnico) se tornou um das práticas essenciais dos estados contemporâneos, incluindo os chamados democráticos. A exceção permanente é uma realidade no Brasil, as pessoas foram afastadas - se é que algum dia estavam presentes - do processo de tomada de decisão, o aspecto normativo da lei é obliterado por uma violência governamental que produz internamente um estado de exceção permanente que, ainda assim, alega estar aplicando a lei. Este exercício sistemático e regular leva necessariamente à liquidação da democracia.

O capitalismo precisa desses mecanismos para manter e continuar gerando lucros, ainda que em detrimento da restrição de direitos e garantias públicas ou direitos sociais. Agora, em vez de se preocupar com o prolongamento da vida do regime, o modelo de garantia do capitalismo está consolidado. Não existe preocupação neste campo com a realização de igualdade de oportunidades e com justiça social. Apesar do horizonte de expectativas decrescentes no Brasil, romper esse movimento de destruição de direitos fundamentais só será possivel com a participação direta nas questões políticas e nos assuntos públicos. A antipolítica e seu projeto de destruição do público representa um projeto de ataque aos direitos sociais. Acreditar que as reformas propostas buscam acabar com os privilégios é uma ilusão. Sobretudo depois de 2016, as medidas de austeridade - que afetam apenas a parte mais pobre da população - são tomadas por meio de um discurso bem elaborado que imputa aos pobres sacrificar ainda mais pelo país em crise.

Como ressaltado, não se trata de minimizar os avanços introduzidos pela Constituição de 1988 em relação aos direitos e garantias fundamentais, mas Bolsonaro e esse projeto de país que ele representa é o preço que todo o país está pagando por não ter uma justiça de transição, uma não reconciliação com seu passado ditatorial. Ódio, repressão, abuso de poder, perseguição política a jornalistas e minorias, destruição total de direitos e garantias fundamentais: esse é o projeto do governo Bolsonaro. Os fascistas brasileiros não têm mais vergonha de se expor: juízes, promotores, advogados, médicos, professores, enfim, pessoas que se alinham à extrema-direita estavam aqui o tempo todo desde o final da ditadura militar brasileira. Ante os vários questionamentos, Agamben (2014a, par. 1) já apontou uma possível resposta durante conferência pública em Atenas, no ano de 2013, abrindo sua fala com a seguinte afirmação: "Uma reflexão sobre o destino da democracia, aqui e hoje, em Atenas é de algum modo perturbante, porque obriga a pensar o fim da democracia precisamente no lugar onde nasceu”. No caso do Brasil, falar em fim da democracia implica dizer que esse conceito já havia se concretizado, no entanto, parece não fazer sentido falar em democracia no Brasil, a menos que repensemos esse conceito.

\section{Referências}

Agamben, G. (2004). Estado de exceção. (Trad. Iraci D. Poleti). São Paulo: Boitempo.

Agamben, G. (2014a). Por uma teoria do poder destituinte. $<$ https://5dias.wordpress.com/2014/02/11/por-umateoria-do-poder-destituinte-de-giorgio-agamben/ $>$.

Agamben, G. (2014b). Como a obsessão por segurança muda a democracia. $<$ http://webserver.diplomatique. org.br/artigo.php?id=1568>

Arantes, P. E. (2007). Estado de sítio. Em: Extinção. São Paulo: Boitempo.

Arantes, P. E. (2010). 1964, o ano que não terminou. Em: Teles, E. e Safatle, V. (Eds.). O que resta da ditadura: a exceção brasileira. São Paulo: Boitempo.

Arantes, P. E. (2014). O novo tempo do mundo: e outros estudos sobre a era da emergência. São Paulo: Boitempo. 
Bercovici, G. (2004). Constituição e estado de exceção permanente: Atualidade de Weimar. Rio de Janeiro: Azougue editorial.

Bercovici, G. (2006). O estado de exceção econômico e a periferia do capitalismo. Pensar. Revista do Curso de Direito da Universidade de Fortaleza, vol. 11, pp. 95-99.

Bercovici, G. (2008). Soberania e Constituição: para uma crítica do constitucionalismo. São Paulo: Quartier Latin.

Bercovici, G. (2010). "O direito constitucional passa, o direito administrativo permanece": a persistência da estrutura administrativa de 1967. Em Teles, E. e Safatle, V. (Eds.). O que resta da ditadura: a exceção brasileira. São Paulo: Boitempo.

Bonavides, P. e Andrade, P. (1991). História Constitucional do Brasil. (3 $3^{\mathrm{a}}$ ed.). Rio de Janeiro: Paz e Terra.

Bueno, R. (2017). Escritos desde a resistência democrática ao golpe de estado de 2016: autoritarismo, neoliberalismo, fascismo e economia. São Paulo: Editora Max Limonad.

Canotilho, J. J. G. (1998). Direito constitucional e teoria da constituição. Coimbra: Almedina.

Giacoia Jr., O. (2008). Notas sobre direito, violência e sacrifício. Doispontos, Curitiba, vol. 5, n. 2, pp. 33-47.

Giacoia Jr., O. (2017). Entre a regra e a exceção: fronteiras da racionalidade jurídica. Em Ramiro, C. H. L. e Bueno, R. (Eds.). Sonhos e pesadelos da democracia em Weimar: tensões entre Carl Schmitt e Hans Kelsen. São Paulo: LiberArs.

Matos, O. (2003). Modernidade: república em estado de exceção. Revista USP, n. 59, pp. 46-53.

Oliveira, R. (2015). Catástrofe da libertação: revoltas e contrarrevolução. Artefilosofia (UFOP), vol. 1, pp. 111-129.

Ramiro, C. H. L. (2016). Estado democrático de direito e estado de exceção: fronteiras da racionalidade jurídica. São Paulo: Editora Mackenzie.

Ramiro, C. H. L. (2017, Junho). Schmitt em Weimar: reflexões sobre a crítica antiliberal a democracia. Carl-Schmitt-Studien, vol. 1, n. 1.

Reale, M. (1986). Defesa da democracia. Folha de S. Paulo, São Paulo, 9. jun. 1986. ANC 88, Pasta jan./ jul. 86. Tendências/debates.

Safatle, V. (2010). Do uso da violência contra o Estado ilegal. Em Teles, E. e Safatle, V. (Eds.). O que resta da ditadura: a exceção brasileira. São Paulo: Boitempo.

Santos, F. e Tanscheit, T. (2019, Julho-Setembro). Quando velhos atores saem de cena: a ascensão da nova direita política no Brasil. Colombia Internacional, 99, pp. 151-186.
Schmitt, C. (1968). La dictadura: desde los comienzos del pensamiento moderno de la soberanía hasta la lucha de clases proletaria. (Trad. J. Díaz Garcia). Madrid: Revista de Ocidente.

Schmitt, C. (1996a). Situação espiritual do sistema parlamentar atual. Em A crise da democracia parlamentar. (Trad. I. Lohbauer). São Paulo: Scritta.

Schmitt, C. (1996b). Teologia Política. Em A crise da democracia parlamentar. (Trad. I. Lohbauer). São Paulo: Scritta.

Silva, J. A. (2009). Curso de Direito Constitucional Positivo. (32 ed.). São Paulo: Malheiros.

Teles, E. (2010). Entre justiça e violência: estado de exceção nas democracias do Brasil e da África do Sul. Em Teles, E. e Safatle, V. (Eds.), O que resta da ditadura: a exceção brasileira. São Paulo: Boitempo.

Zaverucha, J. (2010). Relações civil-militares: o legado autoritário da constituição brasileira de 1988. Em Teles, E. e Safatle, V. (Eds.), O que resta da ditadura: a exceção brasileira. São Paulo: Boitempo. 